12.1

\title{
Субволновые текстурированные поверхности для вывода излучения
}

\section{из волновода}

\author{
(ㄱ Г.В. Вознюк ${ }^{1,2}$, И.Н. Григоренко ${ }^{1,3}$, М.И. Митрофранов ${ }^{1,2,4}$, В.В. Николаев ${ }^{1}$, В.П. Евтихиев ${ }^{1,2}$ \\ ${ }^{1}$ Физико-технический институт им. А.Ф. Иофрфе РАН, Санкт-Петербург, Россия \\ ${ }^{2}$ Университет ИТМО, Санкт-Петербург, Россия \\ ${ }^{3}$ Санкт-Петербургский государственный электротехнический университет „ЛЭТИ“, Санкт-Петербург, Россия \\ ${ }^{4}$ НТЦ микроэлектроники РАН, Санкт-Петербург, Россия \\ E-mail: glebufa0@gmail.com
}

Поступило в Редакцию 9 декабря 2021г.

В окончательной редакции 12 января 2022 г.

Принято к публикации 13 января 2022 г.

\begin{abstract}
Продемонстрирована технология создания текстурированных поверхностей методом ионно-лучевого травления сфокусированным пучком на подложках GaAs (100). Показана возможность гибкого управления формой и профилем формируемых субмикронных элементов текстурированных сред, что впоследствии позволит создать текстурированные поверхности практически любой сложности для реализации поверхностного вывода излучения из волновода. Разработаны оригинальные литографические шаблоны и проведена трехмерная литография. Контроль сформированных литографических рисунков осуществлялся методами оптической, электронной и атомно-силовой микроскопии.
\end{abstract}

Ключевые слова: ионно-лучевое травление, метаповерхность, текстурированная поверхность, литография, поверхностный вывод излучения.

DOI: 10.21883/PJTF.2022.06.52214.19103

Создание лазеров с поверхностным выводом излучения широко востребовано во многих областях. Например, для задач спектроскопии и газоанализа требуются эффективные источники лазерного излучения в ИК-области спектра [1]. Среди всех типов лазерных конструкций наибольшую добротность и малую расходимость излучения в дальнем поле имеют лазеры с кольцевым резонатором [2]. В настоящее время существует ряд подходов по реализации поверхностного вывода излучения: нанесение на поверхность волновода дифракционных порядков [3], формирование фотонных кристаллов [4], создание метаповерхностей [3]. Все эти методы требуют высокой точности и однородности изготовления (например, штрихи дифракционной решетки), а также являются сложными и дорогостоящими в производстве.

Альтернативным подходом в создании поверхностноизлучающих кольцевых лазеров может стать формирование текстурированных поверхностей на поверхности лазерного волновода. Некоторые теоретические работы свидетельствуют о перспективности использования текстурированных поверхностей для эффективного ввода излучения $[5,6]$. Кроме того, текстурированные поверхности могут использоваться в качестве шаблона для создания гибридных плазмонно-диэлектрических структур [7].

Принцип действия текстурированных поверхностей основан на создании плавно меняющегося (градиентного) показателя преломления на границе волновод/воздух, что позволяет на несколько порядков снизить отраже- ние и осуществить поверхностный вывод излучения. Достоинствами такого подхода являются возможность вывода излучения без изменения изначального модового состава лазера, нетребовательность к высокой однородности изготовления отдельных элементов, входящих в состав текстурированной поверхности. Примером текстурированной поверхности может служить двумерный массив, состоящий из элементов конусообразной формы (пирамидок). Главными требованиями к элементам текстуры являются субволновые размеры по отношению к выводимому излучению и как можно более плавное сужение элемента от его основания к вершине для того, чтобы избежать возникновения скачка показателя преломления, а следовательно, условия для отражения света [5]. На рис. 1 показан принцип действия текстурированной поверхности применительно к поверхностному выводу излучения из волновода. Для создания текстурированных поверхностей мы использовали метод ионнолучевого травления сфокусированным ионным пучком (СИП). Литография проводилась на разработанной ЗАО „НТО“ совместно с НТЦ микроэлектроники РАН установке ионно-лучевого травления СИП в сверхвысоковакуумном исполнении „FIB-FEB UHV System“, оборудованной ионной колонной модели „Сobra“ производства компании Orsay Physics. Разрешающая способность растрового ионного микроскопа, согласно паспортным данным, составляет $2.5 \mathrm{~nm}$. В качестве мишени для травления были выбраны полуизолирующие подложки GaAs (100). 


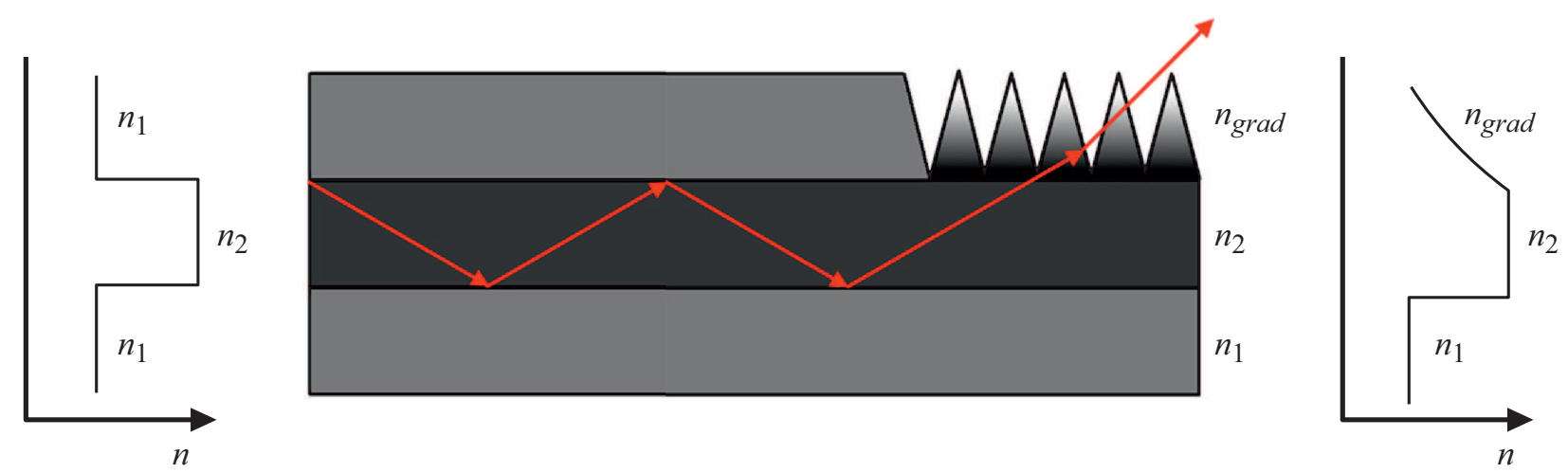

Рис. 1. Принцип действия текстурированной поверхности, сформированной в верхнем слое волновода. Левая часть волновода представляет собой обычный волновод, где в результате полного внутреннего отражения свет остается запертым внутри волновода. Правая часть волновода содержит текстурированную поверхность, которая создает плавно меняющийся (градиентный) показатель преломления, в результате осуществляется вывод излучения через поверхность.

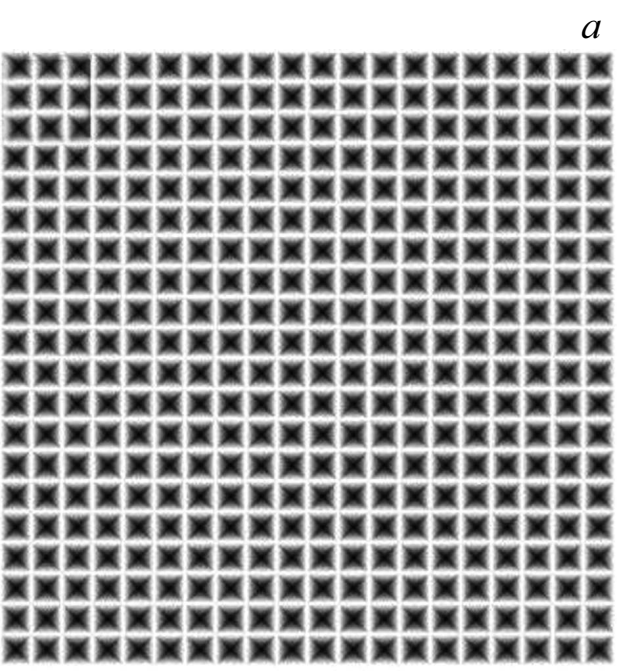

Рис. 2. Литографический шаблон, использующийся при формировании текстурированной среды методом ионно-лучевой литографии СИП. $a$ - общий вид литографического шаблона, $b-$ увеличенное изображение одного элемента (пирамидки) из массива.

Для отработки режимов травления текстурированных поверхностей методом ионно-лучевой литографии СИП был проведен ряд подготовительных работ. С помощью системы автоматизированного проектирования Кompas 3D и графических редакторов (Photoshop, GIMP) были спроектированы и подготовлены литографические шаблоны для ионно-лучевого литографа. На рис. 2 представлен пример разработанного литографического шаблона размером $25 \times 25 \mu \mathrm{m}$, содержащий двумерный массив пирамидок. Принцип травления по представленному шаблону заключается в плавном увеличении времени экспонирования сфокусированным пучком поверхности при переходе от центра пирамидки к ее краям. Градации серого цвета, из которых состоит шаблон, задают время экспонирования, что в свою очередь определяет форму профиля и тип основания формиру- емой пирамидки. Время экспозиции изменялось от $0 \mathrm{~s}$ (черный пиксель) до $5 \cdot 10^{-5} \mathrm{~s}$ (белый пиксель). Была проведена серия экспериментов по подбору технологических параметров литографического процесса. Наилучшей шероховатости травленой поверхности $(>2 \mathrm{~nm})$ и однородности элементов текстуры при относительно невысоких временны́х затратах удалось достичь при рабочем токе $150 \mathrm{pA}$, максимальном времени экспозиции $5 \cdot 10^{-5} \mathrm{~s}$ и перекрытии ионного пучка $75 \%$. Литография проводилась в присутствии газа-прекурсора $\mathrm{XeF}_{2}$ для эффективного удаления остаточных продуктов травления.

Изображения текстурированной поверхности, сформированной методом травления СИП $\mathrm{Ga}^{+}$с энергией $30 \mathrm{keV}$, полученные с помощью оптической и электронной микроскопии, представлены на рис. $3, a, b$. Профиль 

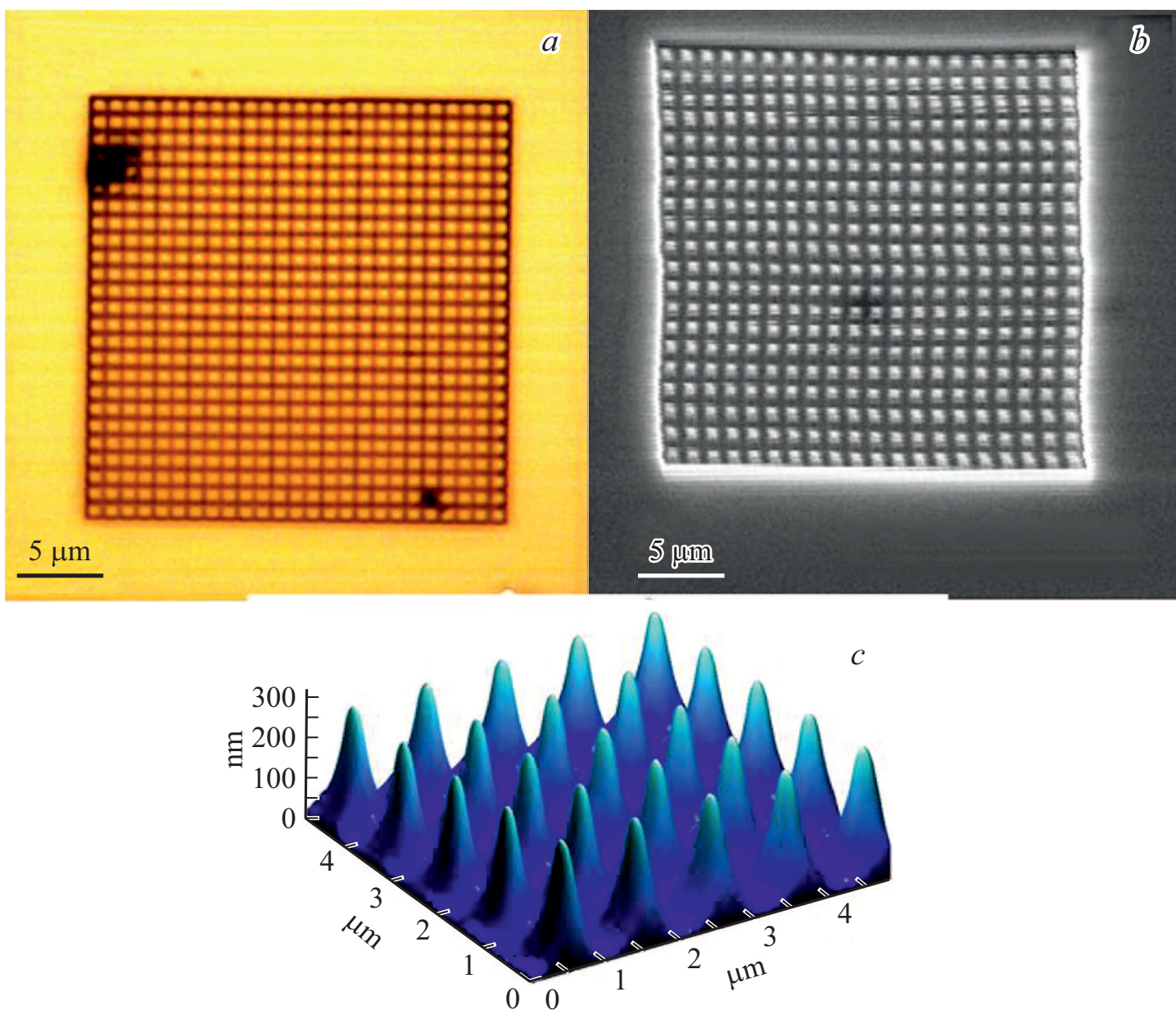

Рис. 3. Изображения текстурированной поверхности, изготовленной в $\mathrm{GaAs}$ методом CИП $\mathrm{Ga}^{+}$c энергией $30 \mathrm{keV}$, полученные с помощью оптической $(a)$ и сканирующей электронной $(b)$ микроскопии. $c$ - трехмерный профиль поверхности, записанный с помощью атомно-силовой микроскопии с участка размером $5 \times 5 \mu \mathrm{m}$.

поверхности, записанный при помощи сканирующего зондового микроскопа модели „Смена“ производства кампании NT-MDT, приведен на рис. 3, $c$.

По результатам проведенного исследования были разработаны литографические шаблоны различного типа сложности, отработаны технологические режимы ионнолучевой литографии СИП $\mathrm{Ga}^{+}$. Определены оптимальные параметры технологического процесса, позволяющие добиться высокого качества формируемых текстурированных поверхностей. Сформированы двумерные массивы пирамидок с размерами основания одного элемента $\sim 500 \mathrm{~nm}$ и высотой элемента $\sim 300 \mathrm{~nm}$ на подложках GaAs (100). Контроль вытравленных поверхностей осуществлялся методами оптической, электронной и атомно-силовой микроскопии. Показана перспективность применения СИП для прототипирования субмикронных элементов, имеющих сложную геометрию. В дальнейшем планируется провести эксперименты по травлению СИП субмикронных и субволновых текстурированных поверхностей на поверхности волноводов и исследовать возможность поверхностного вывода излучения из таких волноводов.

\section{Финансирование работы}

Работа поддержана грантом Российского научного фонда (проект № 21-12-00304).

\section{Конфликт интересов}

Авторы заявляют, что у них нет конфликта интересов.

\section{Список литературы}

[1] D. Popa, F. Udrea, Sensors, 19, 2076 (2019). DOI: $10.3390 / \mathrm{s} 19092076$

[2] R. Szedlak, C. Schwarzer, T. Zederbauer, H. Detz, A.M. Andrews, W. Schrenk, W. Strasser, Appl. Phys. Lett., 104, 151105 (2014). DOI: 10.1063/1.4871520

[3] R. Szedlak, C. Schwarzer, T. Zederbauer, H. Detz, A.M. Andrews, W. Schrenk, W. Strasser, Opt. Express, 22, 15829 (2014). DOI: 10.1364/OE.22.015829 
[4] J. Semmel, L. Nähle, S. Höfling, A. Forchel, Appl. Phys. Lett., 91, 071104 (2007). DOI: 10.1063/1.2771054

[5] A. Deinega, I. Valuev, B. Potapkin, Yu. Lozovik, J. Opt. Soc. Am. A, 28, 770 (2011). DOI: 10.1364/JOSAA.28.000770

[6] J.A. Dobrowolski, D. Poitras, P. Ma, H. Vakil, M. Acree, Appl. Opt., 41, 3075 (2002). DOI: 10.1364/AO.41.003075

[7] J. Gallant, M.A. Kaliteevski, D. Wood, M.C. Petty, R.A. Abram, S. Brand, G.P. Swift, D.A. Zeze, J.M. Chamberlain, Appl. Phys. Lett., 91, 161115 (2007). DOI: 10.1063/1.2800381 